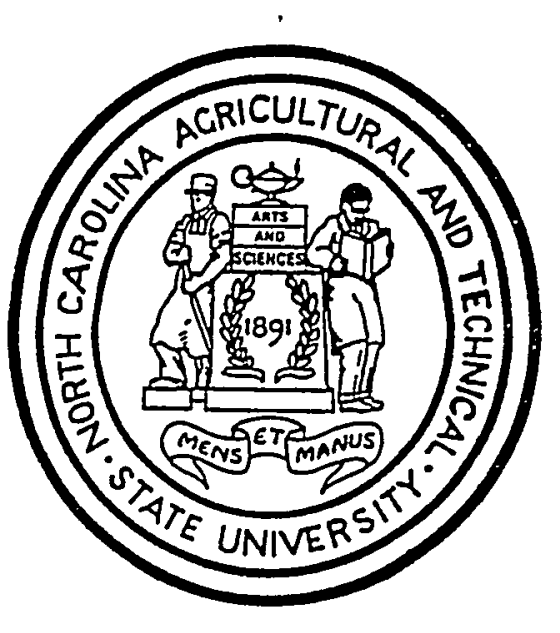

$$
\text { DOF/OR/22119--T) AUG } 211998
$$

\title{
EFFECT OF SAMPLE TEST VOLUME AND GEOMETRY ON THE TENSILE MECHANICAL BEHAVIOR OF SIC/SIC CONTINUOUS FIBER CERAMIC COMPOSITES
}

\section{FINAL REPORT}

Report prepared by

J. Sankar

A. D. Kelkar

Jayant Neogi

North Carolina A \& T State University

Department of Mechanical Engineering

Greensboro, NC 27411

For

U. S. Department of Energy

Oak Ridge National Laboratory

Oak Ridge, Tennessee 37831

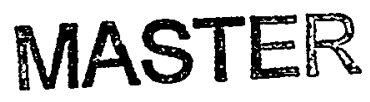

DISTRIBUTION OF THIS DOCUMENT IS UMLIMITEO 


\section{DISCLAIMER}

This report was prepared as an account of work sponsored by an agency of the United States Government. Neither the United States Government nor any agency thereof, nor any of their employees, makes any warranty, express or implied, or assumes any legal liability or responsibility for the accuracy, completeness, or usefulness of any information, apparatus, product, or process disclosed, or represents that its use would not infringe privately owned rights. Reference herein to any specific commercial product, process, or service by trade name, trademark, manufacturer, or otherwise does not necessarily constitute or imply its endorsement, recommendation, or favoring by the United States Government or any agency thereof. The views and opinions of authors expressed herein do not necessarily state or reflect those of the United States Government or any agency thereof. 


\section{DISCLAIMER}

Portions of this document may be illegible electronic image products. Images are produced from the best available original document. 


\title{
EFFECT OF SAMPLE TEST VOLUME AND GEOMETRY ON THE TENSILE MECHANICAL BEHAVIOR OF SIC/SIC CONTINUOUS FIBER CERAMIC COMPOSITES
}

\author{
FINAL REPORT
}

Prepared by

\begin{abstract}
J. Sankar, A. D. Kelkar and Jayant Neogi
North Carolina A \& T State University

Department of Mechanical Engineering

Greensboro, NC 27411
\end{abstract}

\author{
For \\ U.S. Department of Energy \\ Energy Program Division \\ Oak Ridge National Laboratory \\ P. O. Box 2001 \\ Oak Ridge, TN 37831-8785 \\ DoE Grant No. DE-FG05-930R22119
}




\begin{abstract}
The development of a silicon carbide-type fiber from an organometallic precursor has led to a major resurgence of interest in fiber-reinforced ceramic matrix composites. By combining this high strength fiber with a variety of ceramic matrices it has been. possible to achieve tough composites offering significant potential advantages over monolithic ceramics and carbon-carbon for high temperature applications. A continuous-fiber ceramic matrix composite (CFCC) typical of materials proposed for such industrial applications as power generation, heat recovery and chemical production as well as biomedical and environmental applications was tested in uniaxial tension using a universal test machine. Test parameters investigated included: test mode (load versus displacement), test rate $(0.003 \mathrm{~mm} / \mathrm{s}, 0.03 \mathrm{~mm} / \mathrm{s}, 50 \mathrm{~N} / \mathrm{s}$ and 500 $\mathrm{N} / \mathrm{s}$ ), specimen geometry (straight-sided versus reduced-gauge section) and type of specimen volume (long/thin versus short/fat). Typical properties include an average elastic modulus $130 \pm 10 \mathrm{GPa}$, an average proportional limit stress of $45 \pm 20 \mathrm{MPa}$, an average ultimate tensile strength of $180 \pm 20 \mathrm{MPa}$ and an average modulus of toughness of $8.4 \pm 2\left(\times 10^{5}\right) \mathrm{J} / \mathrm{m}^{3}$.
\end{abstract}




\section{Introduction}

For many years researchers have sought to develop tough ceramics whose performance characteristics retain the best properties of their parent ceramics and have the additional quality of not being susceptible to fracture during impact or under stress in the presence of a notch. The addition of fibers to ceramics has been known for many years to be one approach for achieving this goal. The development of fiber reinforced cements is undoubtedly the best known example of this technology. Extension of this concept into higher performance ceramic matrices like CFCCs, has not been nearly as successful ${ }^{1}$.

Early experiments performed in England, Germany and the United States ${ }^{2}$ however, demonstrated that high performance fibers can be successfully incorporated into glasses to achieve high strength, tough, composite materials. Through the use of carbon fibers to reinforced glasses and glass-ceramics, composites with strengths above $700 \mathrm{MPa}$ were demonstrated by 1973. However, due to the fact that at the time of this work carbon fiber reinforced polymers matrix composites were not yet accepted as reliable engineering materials and also due to the oxidative instability of the carbon fibers themselves, these early developments were not carried further. More recently, the researchers have been able to extend this early work, due to the development of new fibers, such as the organometallic derived silicon carbide yarn which have become available and have permitted the creation of composites with superior high-temperature capability, low density, oxidation and corrosion resistance.

The key to the successful development of CFCCs lies in the fact that it has been carried out as a direct extension of metal and resin matrix composites efforts. In each case high elastic modulus fibers have been incorporated into a lower elastic modulus matrix to achieve structural reinforcement. The composites which result from this processing are characterized by high strength, stiffness, toughness and in general, overall performance similar to resin matrix, except that in this case performance can be maintained up to temperatures as high as $1200^{\circ} \mathrm{C}$. In addition, these composites are not expected to be susceptible to environmental degradation due to moisture, oils or fuels.

The argument in favor of continuous fiber ceramic composites has been well documented. However many of these studies are concerned with unidirectional composites having a reinforcing glass matrix. Continuous -fiber composites in multiple directions or braided composites have received less attention ${ }^{3}$.

In polymer matrix composites, where the matrices are ductile and the composite stiffness and strength are dominated by the fibers. For CFCCs, however, the matrix moduli are comparable or even higher than fiber moduli; for example the ceramic matrix composite (CMC) material investigated in the present study, the axial Young's modulus of Nicalon fiber is $190 \mathrm{GPa}$, while that of the SiC matrix is about $400 \mathrm{GPa}$. Also, because of the brittleness of ceramic matrices, CFCCs are susceptible to matrix cracking when the applied tensile load reaches the critical value. Thus, the addition of fibers is intended to improve the toughness rather than the stiffness of the composite. Besides the fibers and matrices, the thermo-mechanical behavior of CFCCs is also affected by processing routes. For example, 
woven CFCCs fabricated by the CVI technique normally contain higher porosity than woven polymer composites fabricated by resin transfer molding. The space not occupied by fiber tows is referred as intertow space, The matrix material in this space is termed the intertow matrix and the pores in the matrix are referred as the intertow pores. The pores within the fiber tows are referred as intratow pores. It was observed that the size of intertow pores is proportional to the size of intertow space, whereas the intratow pores size is of the order of the fiber cross-sectional area, both are dependent on processing condition.

This study, in particular, characterizes various testing parameters and their subsequent effect on the tensile mechanical behavior of a two dimensional woven $\mathrm{SiC} / \mathrm{SiC}$ continuous fiber composite. 


\section{Experimental Investigation}

The particular CFCC in this study was examined under a variety of testing conditions in order to ascertain the response on both the fiber and the matrix. Experimental results examined using a universal test machine include, stress-strain response, proportional limit, ultimate tensile strength, modulus of toughness of the composite and the effect of bending. A servo-hydraulic mechanical test system a equipped with a self-aligning hydraulic grip developed by $O R N L^{4}$ that produces near-zero bending moments $(<0.05 \%$ of the applied tensile stress) was used for conducting the uniaxial tensile tests. The strain was measured using a dual arm clip on type extensometer, thereby returning separate but continuous strain values for two opposing sides of the specimen.

A number of tests were performed on the SiC/SiC CFCC under test modes of varied rate and loading $(0.003 \mathrm{~mm} / \mathrm{s}, 0.03 \mathrm{~mm} / \mathrm{s}, 50 \mathrm{~N} / \mathrm{s}$ and $500 \mathrm{~N} / \mathrm{s})$. Each of the experimental results obtained also included a strain and percent bending for the - specimen. These values are used to determine the effect of test mode, geometry and test rate on the properties of the ceramic composite. It is already known that the strength properties of many engineering materials depend as much on the test methodology as on the materials. This study helps analyze these effects on CFCC's.

The experimental results are compared for the various effects examined and a detailed fractographic analysis that were done on the CFCC's are presented in this paper. The study of this material will provide fundamental mechanical properties and performance for the database of CFCC's as a newly emerging class of materials. In addition, the results will provide critical feedback for the verification of recommendations and requirement of national test standards (e.g. ASTM) for tensile testing of a CFCC.

\section{Material Specification}

The as-tested specimens were machined out of $200 \mathrm{~mm}$ square plates which had been fabricated from 12 plies of two-dimensional plainly woven SiC fiber bundles and densified with a chemically vapor infiltrated (CVI) $\beta$ - SiC matrix into four different test specimen geometry (designated TM4, TM5, TM6 and TM7) (Table 1).

End tabs manufactured from an E-glass fiber/epoxy matrix were attached to the gripped ends of the specimen to protect them from being damaged within the hydraulic grips. Clamping without end tabs can produce premature splitting due to the contact of the grip surface with the specimen. M-Bond $200^{\mathrm{b}}$ which has a shear strength greater than the interfacial shear stress anticipated at the interface of the tab and specimen was used to attach the end tabs to the specimens.

\footnotetext{
"INSTRON 8511, Canton, MA

${ }^{b}$ Measurements Group, Inc., Raleigh, NC
} 
Table 1. As Designed Specimen Dimensions (mm)

\begin{tabular}{|c|c|c|c|c|c|c|}
\hline $\begin{array}{c}\text { Sampl } \\
\text { e ID\# }\end{array}$ & Geometry & $\begin{array}{c}\text { Length } \\
(\mathrm{mm})\end{array}$ & $\begin{array}{c}\text { Width } \\
(\mathrm{mm})\end{array}$ & $\begin{array}{c}\text { Gage Width } \\
(\mathrm{mm})\end{array}$ & $\begin{array}{c}\text { Gage Length } \\
(\mathrm{mm})\end{array}$ & $\begin{array}{c}\text { Gage Volume } \\
\left(\mathrm{mm}^{3}\right)\end{array}$ \\
\hline TM7 & $\begin{array}{c}\text { Reduced Gage } \\
\text { Section }\end{array}$ & 200.15 & $17.96-18$ & $10-10.1$ & 60 & 2220 \\
\hline TM5 & $\begin{array}{c}\text { Reduced Gage } \\
\text { Section }\end{array}$ & 170.18 & $9.04-9.09$ & 5.08 & 60 & 1110 \\
\hline TM4 & $\begin{array}{c}\text { Reduced Gage } \\
\text { Section }\end{array}$ & 141.78 & 18.08 & $9.88-9.95$ & 30 & 1110 \\
\hline TM6 & $\begin{array}{c}\text { Straight } \\
\text { T. }\end{array}$ & 170.18 & $9.86-10$ & $9.86-10$ & 100 & 3700 \\
\hline
\end{tabular}

Note: All specimens are 12 plies thick equivalent to $(3.56-3.81 \mathrm{~mm})$ thick.

\section{Test Methodology}

As per ASTM C1275-94 and E1012 load train alignment was done prior to and at the completion of testing. The purpose of an alignment procedure is to reduce the introduction of bending moments into the specimen during tensile testing. A flat reduced gage section stainless steel tensile specimen was fabricated for use as an alignment specimen. Two contact type extensometer were clamped on the opposing flat faces such that bending could be calculated at the gage section.

The percent bending was calculated using the following equations

$$
\varepsilon_{a v g}=\frac{\varepsilon_{1}+\varepsilon_{2}}{2}
$$

Where $\varepsilon_{\text {avg. }}$ is the average axial strain, $\varepsilon_{1}$ and $\varepsilon_{2}$ are the opposing strains on the opposite faces. The local bending strain is equal to the local strain reading minus the axial strain. The maximum bending strain is

$$
\varepsilon_{B}= \pm\left(\frac{\varepsilon_{1}-\varepsilon_{2}}{2}\right)
$$

and then

$$
\left(\frac{\varepsilon_{B}}{\varepsilon_{\text {avg }}}\right) \times 100=P B
$$

Where the PB is the standard notation for percent bending. The PB that were calculated in our test setup at the beginning and at the end of the test series showed values less than $5 \%$ at $500 \mu \mathrm{m} / \mathrm{m}$ as required by ASTM C 1275 .

The modulus of elasticity was calculated using a least square, linear regression from the slope of the linear portion of a stress-strain curve from 0 to $15 \mathrm{MPa}$. The stress range of 0 to $15 \mathrm{MPa}$ was chosen for all the curves since $15 \mathrm{MPa}$ was found to be the least value of 
the proportional limit stress of all the curves. Thus, it was assumed that the stress region of 0 to $15 \mathrm{MPa}$ would always represent the linear region.

The proportional limit stress $\sigma_{0}$, is a critical parameter in comparing ceramic composites because the stress-strain response of a material is linear up to the proportional limit. In CFCC's it can be argued that the proportional limit stress is the most important design parameter because, similar to the yield point in a metal, it defines the stresses at the onset of nonlinearity. However, unlike the yield point in metals, the proportional limit in CFCC's can be equated to the first matrix cracking strength which delineates the offset of the cumulative damage underlying the non-linear stress-strain response. To calculate the proportional limit stress the following approach was used:

A stress is calculated as the product of the elastic modulus and the actual strain. The proportional limit is the point at which the difference between the actual stress $\left(\sigma_{i}\right)$ and the calculated stress $(\sigma)$ is equal to $10 \%$. Where actual stress $\left(\sigma_{i}\right)$ and actual strain $\left(\varepsilon_{i}\right)$ are obtained from the test data.

$$
\begin{gathered}
\sigma=E \varepsilon_{i} \\
\text { when }\left(\left(\frac{\sigma_{i}-\sigma}{\sigma}\right) \times 100\right) \geq 10 \%
\end{gathered}
$$

The total energy that the material absorbs up to final fracture is the modulus of toughness. It can be defined by the following equation:

$$
U_{T}=\int_{0}^{\varepsilon} \sigma d \varepsilon
$$

Where $U_{T}$ is the modulus of toughness, $\sigma$ is the tensile stress, $\varepsilon$ is the tensile strain and $\varepsilon_{f}$ is the strain at fracture. The above equation represents the area under the entire stress-strain curve and has units of $\mathrm{J} / \mathrm{m}^{3}$.

To evaluate the effect of test rate, an order of magnitude difference was chosen between the minimum and maximum test rates. However, in order to compare differences in test modes (displacement versus load control), the same approximate time to failure was used, i.e. after conducting an initial test under displacement control of say $0.003 \mathrm{~mm} / \mathrm{s}$, based on the obtained strength, strain and the time to failure, an approximate loading rate was calculated. Thus establishing time to failure for each geometry, it is thought that more meaningful data can be obtained when we compare strength and strain results. The final displacement and load rates chosen were $0.003 \mathrm{~mm} / \mathrm{s}, 0.03 \mathrm{~mm} / \mathrm{s}, 50 \mathrm{~N} / \mathrm{s}$ and $500 \mathrm{~N} / \mathrm{s}$. 


\section{Results and Discussion}

\section{Mechanical Test Results}

Using the setup ${ }^{5}$ raw data values of force, displacement, strain1 and strain2 were gathered. With this information stress, average strain and percent bending (PB) were calculated for the entire range of the test. The properties used in comparing each specimen included a stress-strain/percent bending curve for each specimen. During the mechanical testing, the room temperature and relative humidity were recorded to be between $20-22^{\circ} \mathrm{C}$ and $65-70 \%$ respectively.

Table 2, shows the average estimated time to failure for the four type of specimen geometry under consideration. It was observed that straight edge specimen (TM6) showed the same time to failure i.e. under load control $(50 \mathrm{~N} / \mathrm{s})$ and displacement control $(0.003 \mathrm{~mm} / \mathrm{s})$. Figure 1 shows a typical engineering stress-strain and PB-engineering strain curve. The engineering stress-strain response was generally linear up to the proportional limit stress after which the stress increased at a much slower rate to the ultimate stress. Careful experiments conducted by Kim and Pagano have recently revealed, however, that ceramic-matrix composites develop damage in the form of microcracks at applied stresses well below the observed proportional limits on the stress-strain curves, i.e. within the initial elastic regime. Further, these microcracks increases in number and size with increasing load. In the context of this picture of the damage accumulation process, the transition from elastic to inelastic regime on the stress-strain curve is a consequence of the overall decrease in the elastic modulus of the composite due to bulk damage accumulation rather than due to the extension of a single fully-bridged crack. Probably after the initial matrix cracking, the subsequent stress-strain relation appeared to be linear inspite of the hundreds of non-steady-state cracks that develops in the gage section. This was attributed to the small strain energy contributed by the cracks as compared to the strain energy of the not cracked bulk.

Table 2. Average estimated time to failure.

\begin{tabular}{|c|c|c|c|c|}
\hline Sample & \multicolumn{2}{|c|}{ Displacement Control } & \multicolumn{2}{c|}{ Load Control } \\
\hline ID \# & $0.003 \mathrm{~mm} / \mathrm{s}$ & $0.03 \mathrm{~mm} / \mathrm{s}$ & $50 \mathrm{~N} / \mathrm{s}$ & $500 \mathrm{~N} / \mathrm{s}$ \\
\hline TM7 & 220 & 28 & 165 & 20 \\
\hline TM5 & 240 & 32 & 170 & 14 \\
\hline TM4 & 210 & 25 & 200 & 22 \\
\hline TM6 & 180 & 20 & 180 & 20 \\
\hline
\end{tabular}


Table 3a. Average mechanical property values (displacement control mode)

\begin{tabular}{|c|c|c|c|c|c|c|c|c|c|c|}
\hline $\begin{array}{c}\text { Sample } \\
\text { ID\# }\end{array}$ & $\begin{array}{c}\text { Elastic } \\
\text { Modulus } \\
(\mathrm{GPa})\end{array}$ & \multicolumn{2}{c|}{$\begin{array}{c}\text { Proportional } \\
\text { Limit Stress } \\
\left(\sigma_{0}\right)(\mathrm{MPa})\end{array}$} & \multicolumn{2}{c|}{$\begin{array}{c}\text { Ultimate Tensile } \\
\text { Strength } \\
(\mathrm{MPa})\end{array}$} & \multicolumn{2}{c|}{$\begin{array}{c}\text { \% Failure Strain } \\
\text { (micron) }\end{array}$} & $\begin{array}{c}\text { Modulus of } \\
\text { Toughness } \\
\left(\times 10^{5} \mathrm{~J} / \mathrm{m}^{3}\right)\end{array}$ \\
\hline & $\mathrm{D}_{1}$ & $\mathrm{D}_{2}$ & $\mathrm{D}_{1}$ & $\mathrm{D}_{2}$ & $\mathrm{D}_{1}$ & $\mathrm{D}_{2}$ & $\mathrm{D}_{1}$ & $\mathrm{D}_{2}$ & $\mathrm{D}_{1}$ & $\mathrm{D}_{2}$ \\
\hline TM7 & 126 & 142 & 38 & 40 & 188 & 206 & 62.34 & 67.23 & 9.5 & 7.9 \\
\hline TM5 & 132 & 136 & 58 & 60 & 164 & 174 & 73.54 & 108.88 & 9.9 & 6.4 \\
\hline TM4 & 137 & 138 & 56 & 68 & 153 & 165 & 143.76 & 162.69 & 7.8 & 9.6 \\
\hline TM6 & 128 & 128 & 60 & 62 & 174 & 183 & 65.06 & 80.52 & 6.9 & 7.6 \\
\hline
\end{tabular}

Note: where $D_{i}$ is the displacement rates, $D_{1}=0.003 \mathrm{~mm} / \mathrm{sec}$ and $D_{2}=0.03 \mathrm{~mm} / \mathrm{sec}$

Table 3b. Average mechanical property values (load control mode)

\begin{tabular}{|l|l|l|l|l|l|l|l|l|l|l|}
\hline $\begin{array}{l}\text { Sample } \\
\text { ID\# }\end{array}$ & $\begin{array}{l}\text { Elastic } \\
\text { Modulus } \\
(\mathrm{GPa})\end{array}$ & \multicolumn{3}{|l|}{$\begin{array}{l}\text { Proportional } \\
\text { Limit Stress } \\
\left(\sigma_{0}\right)(\mathrm{MPa})\end{array}$} & \multicolumn{2}{l}{$\begin{array}{l}\text { Ultimate } \\
\text { Strength } \\
(\mathrm{MPa})\end{array}$} & \multicolumn{2}{l|}{$\begin{array}{l}\text { \% Failure Strain } \\
\text { (micron) }\end{array}$} & \multicolumn{2}{l}{$\begin{array}{l}\text { Modulus of } \\
\text { Toughness } \\
\left(\times 10^{5} \mathrm{~J}^{3} \mathrm{~m}^{3}\right)\end{array}$} \\
\hline & $\mathrm{L}_{1}$ & $\mathrm{~L}_{2}$ & $\mathrm{~L}_{1}$ & $\mathrm{~L}_{2}$ & $\mathrm{~L}_{1}$ & $\mathrm{~L}_{2}$ & $\mathrm{~L}_{1}$ & $\mathrm{~L}_{2}$ & $\mathrm{~L}_{1}$ & $\mathrm{~L}_{2}$ \\
\hline TM7 & 128 & 136 & 25 & 35 & 190 & 211 & 47.35 & 58.12 & 6.8 & 7.0 \\
\hline TM5 & 134 & 142 & 32 & 48 & 172 & 190 & 62.78 & 78.38 & 7.4 & 7.5 \\
\hline TM4 & 136 & 142 & 34 & 40 & 159 & 166 & 132.62 & 139.88 & 8.5 & 8.5 \\
\hline TM6 & 140 & 141 & 39 & 42 & 178 & 184 & 62.49 & 64.77 & 7.2 & 7.1 \\
\hline
\end{tabular}

Note: Where $L_{i}$ is the loading rates, $L_{1}=50 \mathrm{~N} / \mathrm{sec}$ and $L_{2}=500 \mathrm{~N} / \mathrm{sec}$

Table $3 a$ and $b$ lists the elastic modulus, proportional limit, ultimate tensile strength, failure strain and modulus of toughness under displacement and load control respectively. The tensile test results as listed in table $3 a$ and $b$ shows that, the ultimate tensile strength of the sample increased slightly as we increased the sample length both under displacement control and load control mode. This trend can be observed in Figure 2. While the ultimate strain followed a reverse trend compared to ultimate tensile strength, as shown in Figure 3 , which showed a significant change in strain as we decreased the length of the sample. Figure 2 and 3 , also showed a trend that as we increased the loading/displacement rated the observed ultimate tensile strength is always higher.

Also, in general there was a lower fracture strength and higher fracture strain under displacement control than for load control due to the relaxation of the strain in displacement control whereas under load control the test machine continues to pull the specimen until interlocks are engaged. The variation of ultimate tensile strength ( $\left.\sigma_{u t s}\right)$ with geometry indicated that $\sigma_{\text {uts }}$ rest on the strength of the fibers. Also the specimens those didn't separate at fracture, the modulus of toughness $\left(U_{T}\right)$ was higher because as the material began to fail, the fibers continued to carry the load after the matrix separation (Figure 4 and 5). Also, figure 4 and 5, show that under different time to failure conditions (i.e. under different loading/displacement rates) the trend of lower fracture strength and higher fracture strain under displacement control than for load control is still maintained.

For each stress-strain curve the modulus of elasticity was calculated using a least squares, linear regression fro the slope of the linear portion of a stress-strain 
curve from 0 to $15 \mathrm{MPa}$. The stress range of 0 to $15 \mathrm{MPa}$ was chosen for all the curves since $15 \mathrm{MPa}$ was found to be the least value of the proportional limit stress of all the curves. Thus, it was assumed that the stress region of 0 to $15 \mathrm{MPa}$ would always represent the linear region. As can be seen in figure 6 , the elastic modulus of the material has very little variation within the data set, as would be expected for material property.

Figure 7, represents the proportional limit stress for both the displacement/load control tests. It can be observed that tests conducted under displacement control showed a higher proportional limit stress than load control test. Also a trend was observed, that as the load or displacement control test rates are increased, there is a slight increase in the proportional limit stress (Figure 7).

The modulus of toughness is a measure of the total energy that the material absorbs up to final fracture. Figure 8 , represents the modulus of toughness measured for both the displacement/load control tests. It can be concluded from Figure 8 , that the modulus of toughness values are consistent between the other test modes and rates.

For a constant gage length (gage length $=60 \mathrm{~mm}$ ), Figure 9 and 10, shows the variation of ultimate stress and strain with respect to gage width. It can be observed that as the gage width of the sample is increased the ultimate stress increases, while the ultimate strain of the sample decreases.

Similarly, for a constant gage width (gage width $=10 \mathrm{~mm}$ ), Figure 11 and 12, shows the variation of ultimate stress and strain with respect to gage length. It can be observed that as the gage length of the necked sample is increased the ultimate stress increases, while the ultimate strain of the sample decreases. It is also observed the same trend is not followed if the sample is not necked. A straight sample showed a much lower ultimate stress and higher ultimate strain, compared to what it would have shown if the sample was necked.

Also, for a constant gage volume (gage volume $=1110 \mathrm{~mm}^{3}$ ), Figure 13 and 14 , shows the variation of ultimate stress and strain with respect to gage length. It can be observed that as the gage length of the sample is increased the ultimate stress increases, while the ultimate strain of the sample decreases. 


\section{Microstructural and Fracture Analyses}

Fractography studies were conducted using a JEOL 6400 field emission scanning electron microscope The sections used for analyses in the gage section were, a) fracture surface, b) a polished section $2 \mathrm{~mm}$ below the fracture surface along the transverse (perpendicular to stress axis) direction. It has been observed that when the composite is subjected to an axial tensile loading, cracks occur first in the matrix at the intertow pores due to stress concentration. As the load increases, the cracks usually propagate within the transverse tow(TT), and then they are arrested at the longitudinal tow(LT)/transverse tow(TT) interfaces due to the fibers in the LT. This results in transverse cracks in the $T$. After the first crack forms in the $\pi$, there are several possible damage mechanisms as the load increases. The activation of the mechanisms depends on the tows fracture toughness, TT/LT interface bonding strength and pore distribution. Experimental evidence using replicate technique shows that additional transverse cracks form at intratow pores, resulting in multiple cracking in the $\Pi$. At the final stage of loading, the transverse cracks propagate into the LT, resulting in matrix cracking, interfacial debonding and fiber breakage. Once fiber breakage's occur, the LT and eventually the composite are close to final failure.

A small amount of porosity (intratow pores) is present within fiber bundles due to fiber contact, which results in sealing during the $\mathrm{CVI}$ interface coating processing step. Hence, there is no access for matrix growth in these regions ${ }^{8}$. Matrix infiltration of very fine regions, including sub-micron sizes, does occur as long as the regions are accessible to the growth front and oxygen. The high magnification micrograph exhibits a range of fiber diameters from $\sim 10-20 \mu \mathrm{m}$, with a majority of fibers in the 15-20 $\mu \mathrm{m}$ diameter range (Figure 15). The $\mathrm{SiC}$ fiber had been coated with $0.4 \mu \mathrm{m}$ thick layer of pyrolytic graphite layer which is relatively weak and consequently imparts high fracture toughness to the composites by allowing crack deflection to occur from matrix to fiber. It is important to control the fiber/matrix interface in these composites to achieve relatively weak interfacial binding (for crack deflection and fiber pullout or sliding) while maintaining oxidative stability at high temperature.

Figure 16 shows a typical fracture surface of a specimen which was tensile tested at ambient temperature. An as-fracture, cross-section surface of the composite is shown in Figure 17. Fiber pull-out, clean debonded fiber-matrix interfaces and a stepped fracture surface are apparent. The step fracture surface was a clear indication of crack deflection by the fibers during the crack propagation. Figure 18 shows the process of crack propagation and deflection. The crack always propagated from one fiber to the next and were diverted by the fiber. An equally important factor for CFCCs in Figure 19, relates to toughness and flaw tolerance. If the interface were too strong, when matrix cracks formed normal to the fibers, they would have propagated in a planar mode through the fibers, giving brittle behavior similar to that in monolithic glasses and ceramics. The CFCCs i.e. under investigation is a high-modulus, brittle matrix system having a sufficiently low interfacial bond strength, which helps the fibers to debond before cracks propagate through them and cracks are deflected parallel to the fibers. It has been also observed that the opening of the large matrix cracks is resisted in part by work done against friction as the matrix slides relative to the unbroken, bridging fibers. Thus, both the tendency to initiate debonding and 
the subsequent resistance to sliding of the matrix relative to the fibers appear to be important factors in determining the working stress range of CFCCs.

Figure 20 shows that the load carrying fiber $0^{\circ}$ (LT) surface was severely damaged compared to $90^{\circ}(T T)$ fibers during room temperature tensile test. The abrasion may be caused by two ways, i) due to fractional movement between debonded fibers and adjacent matrix, which may gradually degraded the strength of load carrying fiber and cause final failure of tested specimens. Another interesting phenomenon, internal heating may be also related to such frictional movement. ii) when the applied load level during the tensile test is above the proportional limit, tensile damage initiation is dominated by fiber debonding and transverse matrix cracking. It is possible that above the proportional limit the broken debris from the debonded matrix rubbing against the load carrying fiber caused the abrasion and subsequent fiber fracture as seen in Figure 20.

Figure 21 shows a high resolution micrograph of the load carrying fiber pull-out region. It shows that the interface between the nicalon fiber and the graphite coating was not damaged during the fiber pull-out. The abrasion caused to the load carrying fibers were only due to its rubbing against the matrix and not due to its rubbing action against the coating. Figure 22 shows the typical surface morphology of fractured fiber in the composites which was tensile tested at ambient temperature. It is also observed that the fiber fracture was mostly surface flaw initiated. 


\section{Conclusions}

Tensile tests were performed using a uniaxial test machine for SiC/SiC continuous-fiber ceramic matrix composites of varying geometry. The strength of the material seems to be affected by the volume of the gage section. A minor increase in ultimate tensile stress was observed for specimens with smaller volume and for faster. loading rates. Also, in general there was a lower fracture strength under displacement control than for load control due to the relaxation of the strain in displacement control whereas under load control the test machine continues to pull the specimen until interlocks are engaged. The measured strain values and hence the percent bending were found to vary due to the difficulty of using the mechanical extensometer in conjunction with the surface of the 2D-woven $\mathrm{SiC} / \mathrm{SiC}$ composite. Typical value of the proportional limit stress were observed to be $\sim 40 \mathrm{MPa}$. It was also observed that the proportional limit stress were higher under displacement control as compared to load control test. The observed elastic modulus were $~ 135 \mathrm{GPa}$. The ultimate tensile strength were found to be $\sim 182 \mathrm{MPa}$. The fracture strength coincided directly with the ultimate strength for all the load control test and the displacement control tests that were conducted at $0.03 \mathrm{~mm} / \mathrm{s}$. The displacement control tests that were conducted at $0.003 \mathrm{~mm} / \mathrm{s}$ showed an unloading stress-strain curve region?

Microstructural observations showed that cracks occurred first in the matrix at the intertow pores due to stress concentration. At the final stages of loading, the transverse cracks propagated into the longitudinal tows, resulting in matrix cracking, interfacial debonding and fiber breakage, which eventually lead to the final failure of the composite. It was observed that there was a wide variation in the fiber diameters from $\sim 10-20 \mu \mathrm{m}$, with a majority of fibers in the $15-20 \mu \mathrm{m}$ diameter range. A weak 0.4 $\mu \mathrm{m}$ thick layer of pyrolytic graphite imparts high fracture toughness to the composite by allowing crack deflection to occur from matrix to fiber. The load carrying fiber surface were severely damaged may be due to the rubbing with the debonded matrix. Also it was observed that the load carrying fiber fractured mostly due to surface flaw which may have been induced due to the rubbing action of the fiber with the debonded matrix. 


\section{References}

1. K. M. Prewo, J. J. Brennan and G. K. Layden, "Fiber Reinforced Glasses and GlassCeramics for High Performance Applications," Ceramic Bulletin, Vol. 65, No. 2, pp. 305313 (1986).

2. R. A. Sambell, D. Bowen and D. C. Phillips, "Carbon Fiber Composites with Ceramic and Glass Matrices, Part 1, Discontinuous Fibers," J. Mat. Sci., 7, pp. 663-675 (1972). 3. M. G. Jenkins, J. P. Piccola Jr., M. D. Mello, E. Lara-Curzio and A. A. Wereszcak, "Mechanical Behavior of a 3-D Braided Continuous SiC Fiber-Reinforced/CVI SiC Matrix Composite at Ambient and Elevated Temperatures," Ceram. Eng. Sci. Proc., 15, Vol. 4, pp. 209-218 (1994).

4. K. C. Liu and C. R. Brinkman, "Tensile Cyclic Fatigue of Structural Ceramics," Proceedings of the Twenty Third Automotive Technology Development Contractors' Coordination Meeting, Society of Automotive Engineers, Warrendale PA, P-16, pp. 279-284 (1985).

5. J. Neogi, "Mechanical Properties Investigation of a Hot Isostatically Pressed (HIPed) Silicon Nitride," M. S. Thesis (1994).

6. L. H. Chao and D. K. Shetty, "A Computational Model or Progressive Damage and Failure of Fiber-Reinforced Ceramic," Final Report Published by Wright Laboratory WL-TR-95-3044 (1995).

7. M. G. Jenkins and E. Lara-Curzio, "Standardized Thermo-Mechanical Test Methods for CFCCs, "Durability and Damage Tolerance, ASME Winter Meeting, 43, pp. 191-211 (1994).

8. D. S. Beyerele, S. M. Spearing and A. G. Evans, "Damage Mechanisms and the Mechanical Properties of a Laminated 0/90 Ceramic/Matrix Composite," J. Am. Ceram. Soc., 75, Vol. 12, pp. $3321-3330$ (1992). 


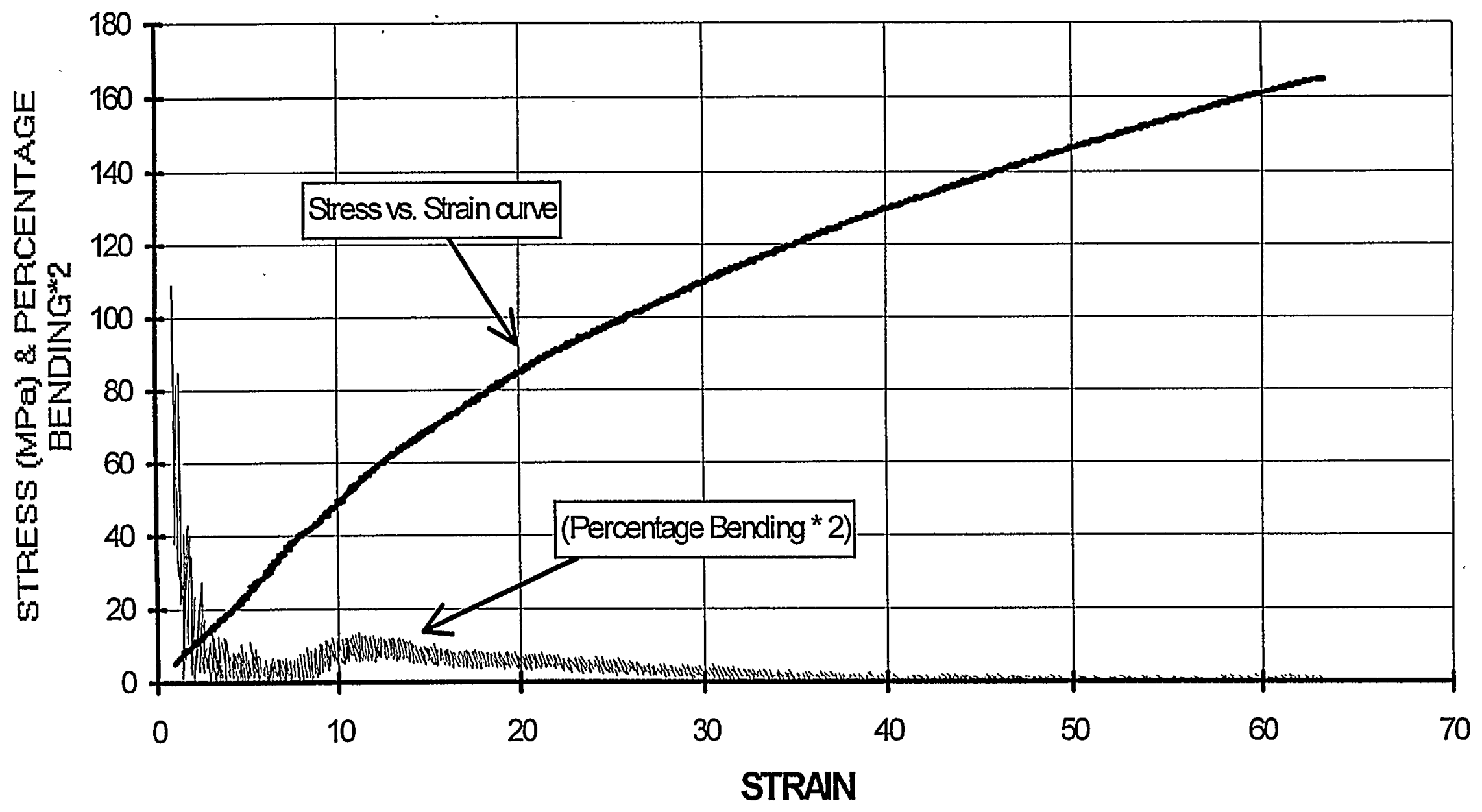

Figure 1. A typical engineering stress-strain and PB-engineering strain curve 


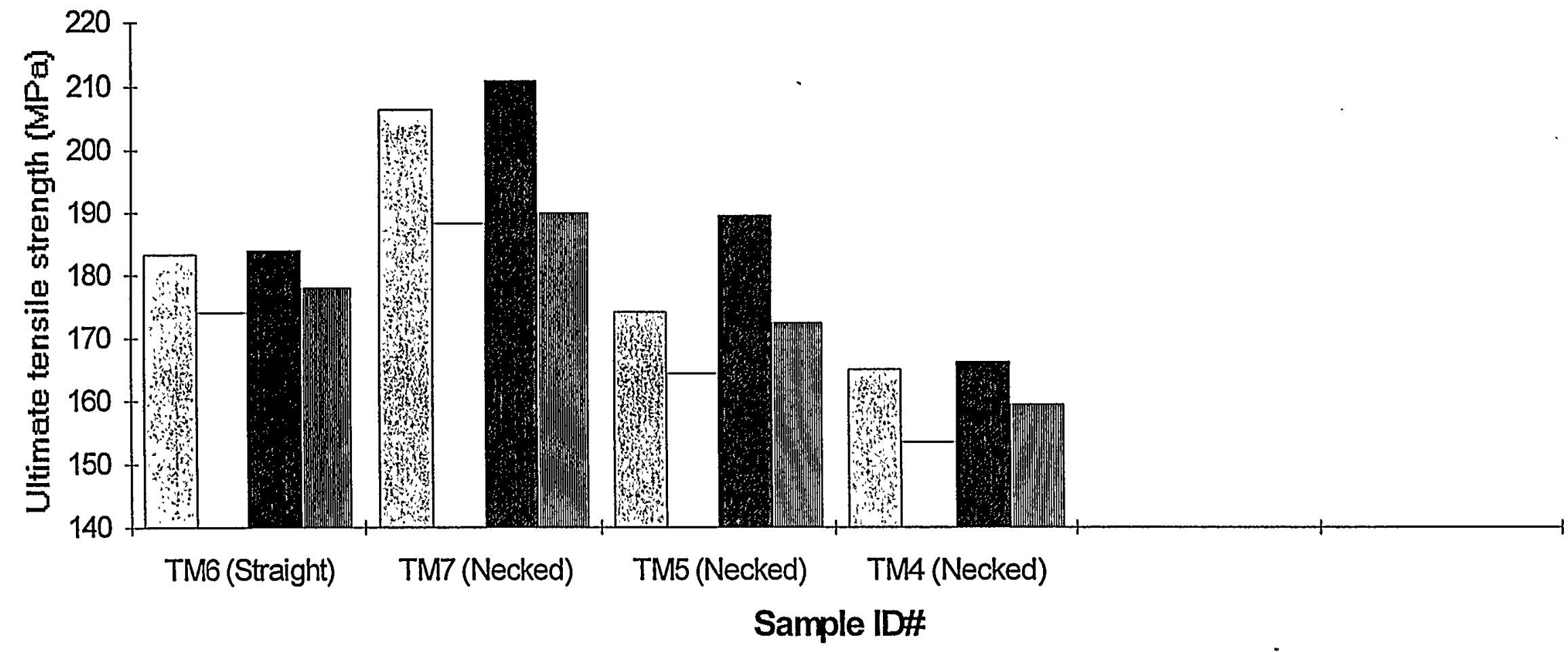

Stress $(D C=0.03 \mathrm{~mm} / \mathrm{sec})$

Stress $(D C=0.003$

Stress ( $L C=500 \mathrm{~N} / \mathrm{sec})$

Stress $(L C=50 \mathrm{~N} / \mathrm{sec})$ $\mathrm{mm} / \mathrm{sec})$

Figure 2. Comparison of Ultimate Tensile Strength for different sample geometry 


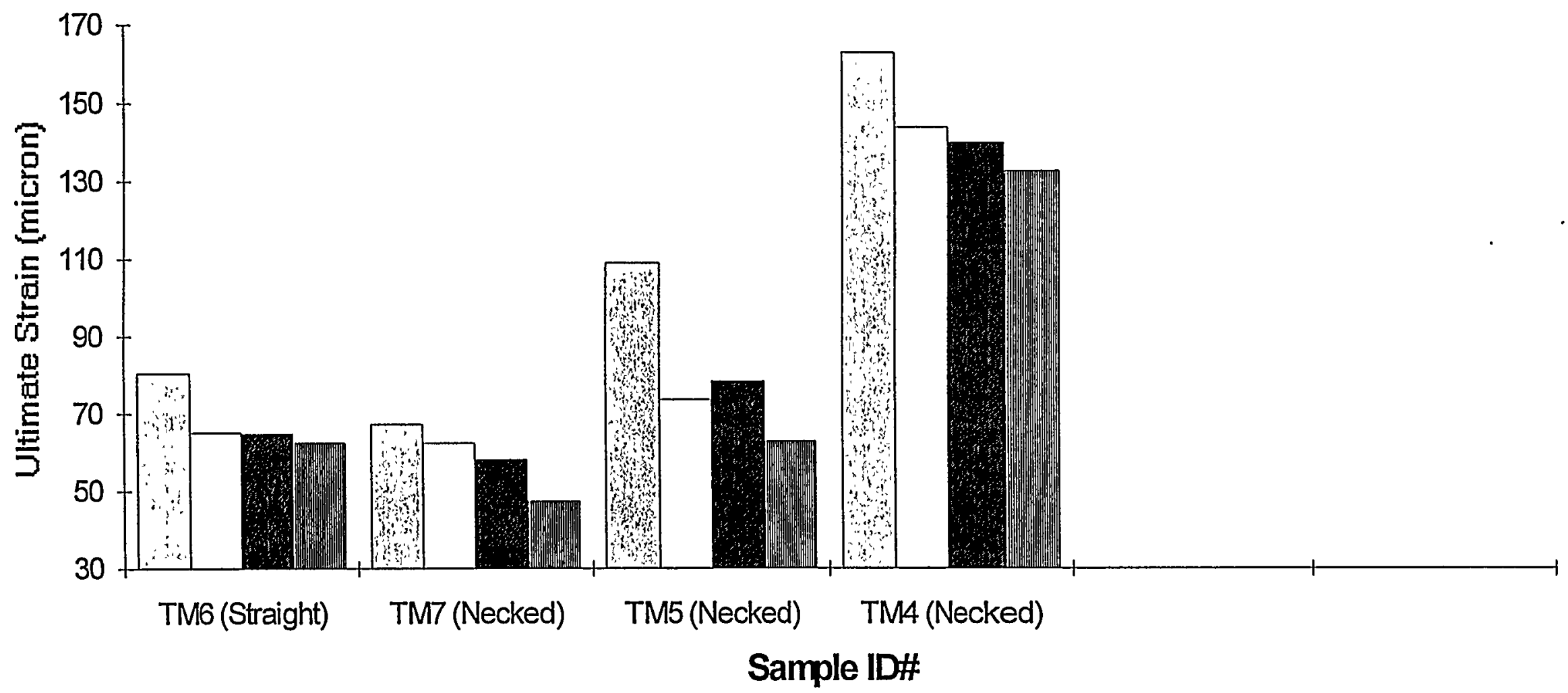

$\square \operatorname{Strain}(D C=0.03 \mathrm{~mm} / \mathrm{sec}) \quad \square \operatorname{Strain}(\mathrm{DC}=0.003 \mathrm{~mm} / \mathrm{sec})$ Strain (LC=500 N/sec) 四 Strain (LC=50 N/sec)

Figure 3. Comparison of Ultimate Strain for different sample geometry 


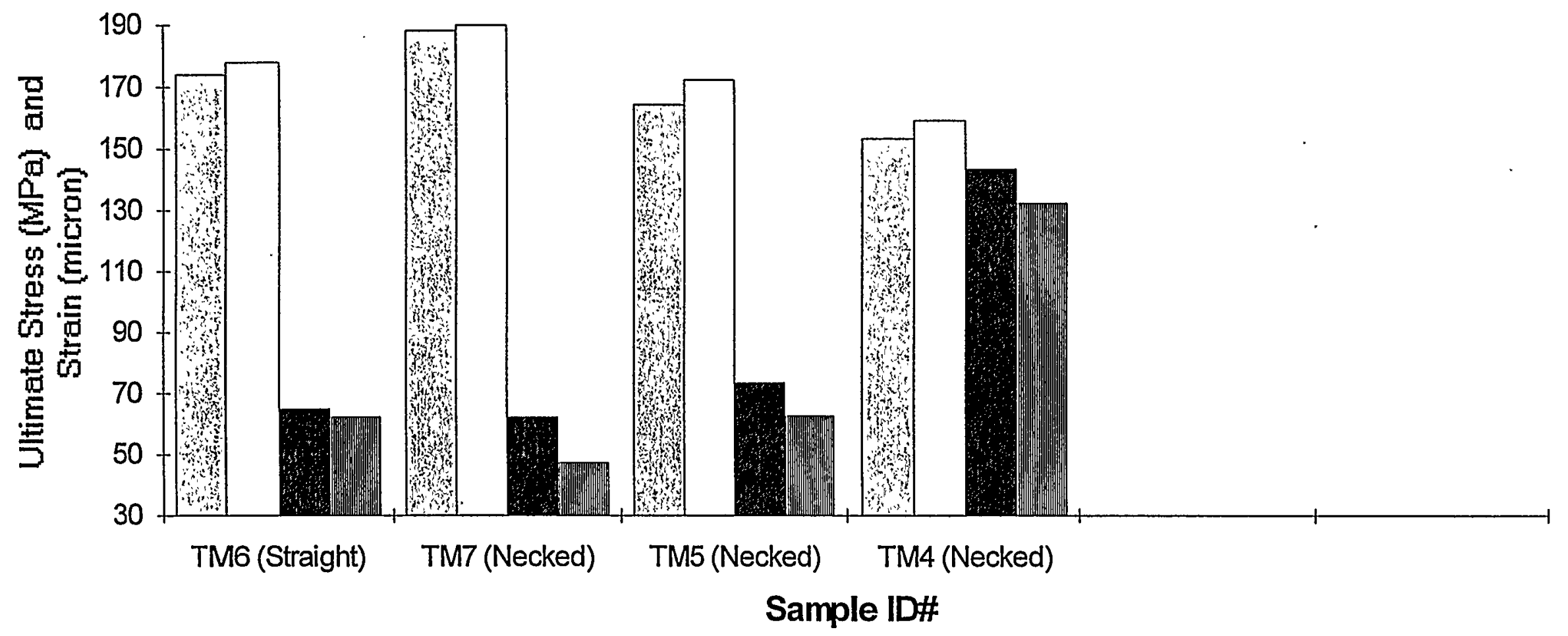

Figure 4. Comparison of Ultimate Tensile Strength and Strain for different sample geometry (condition : Same time to failure 


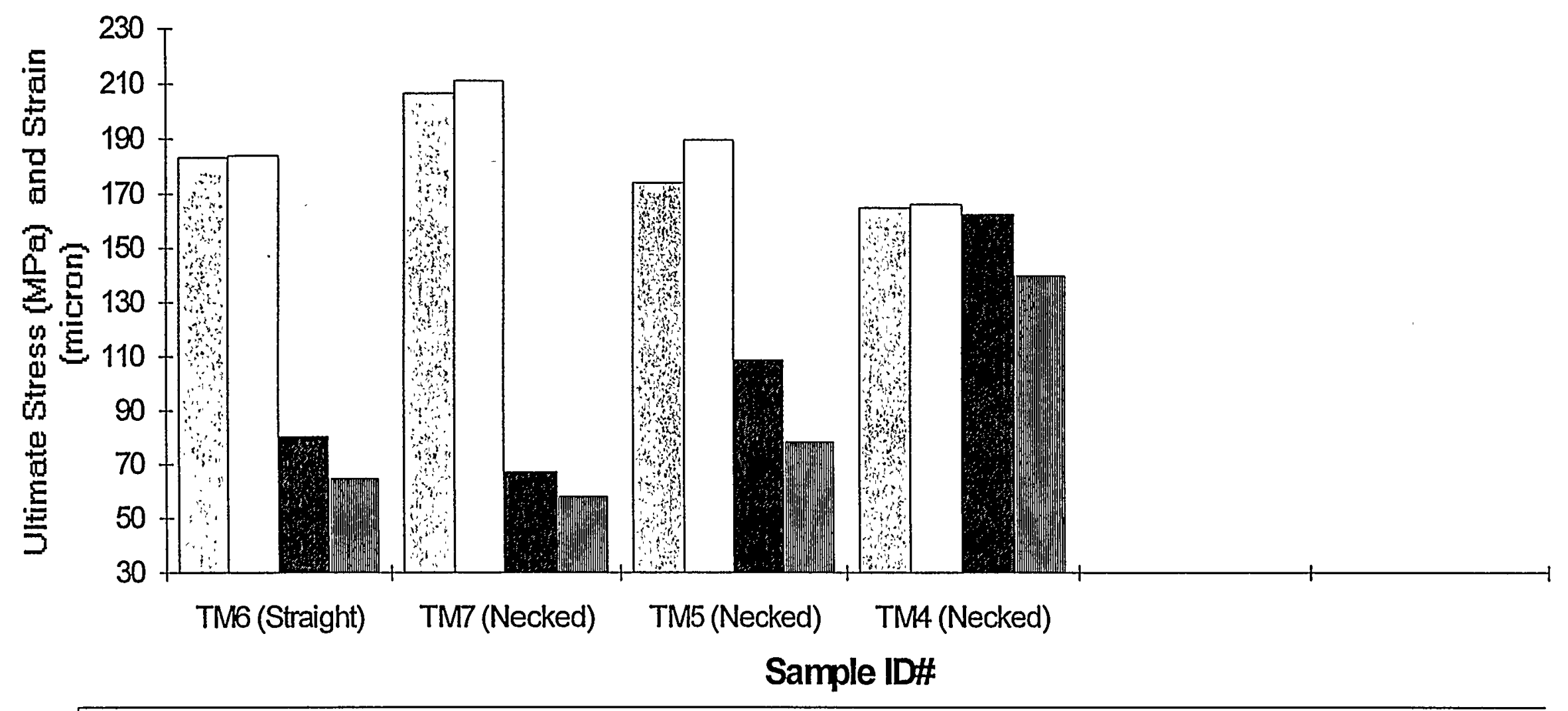

Stress $(\mathrm{DC}=0.03 \mathrm{~mm} / \mathrm{sec}) \quad \square$ Stress $(\mathrm{LC}=500 \mathrm{~N} / \mathrm{sec}) \quad$ Strain $(\mathrm{DC}=0.03 \mathrm{~mm} / \mathrm{sec}) \quad$ 四 Strain $(\mathrm{LC}=500 \mathrm{~N} / \mathrm{sec})$

Figure 5. Comparison of Ultimate Tensile Strength and Strain for different sample geometry (condition : Same time to failure $\sim 21$ seconds) 


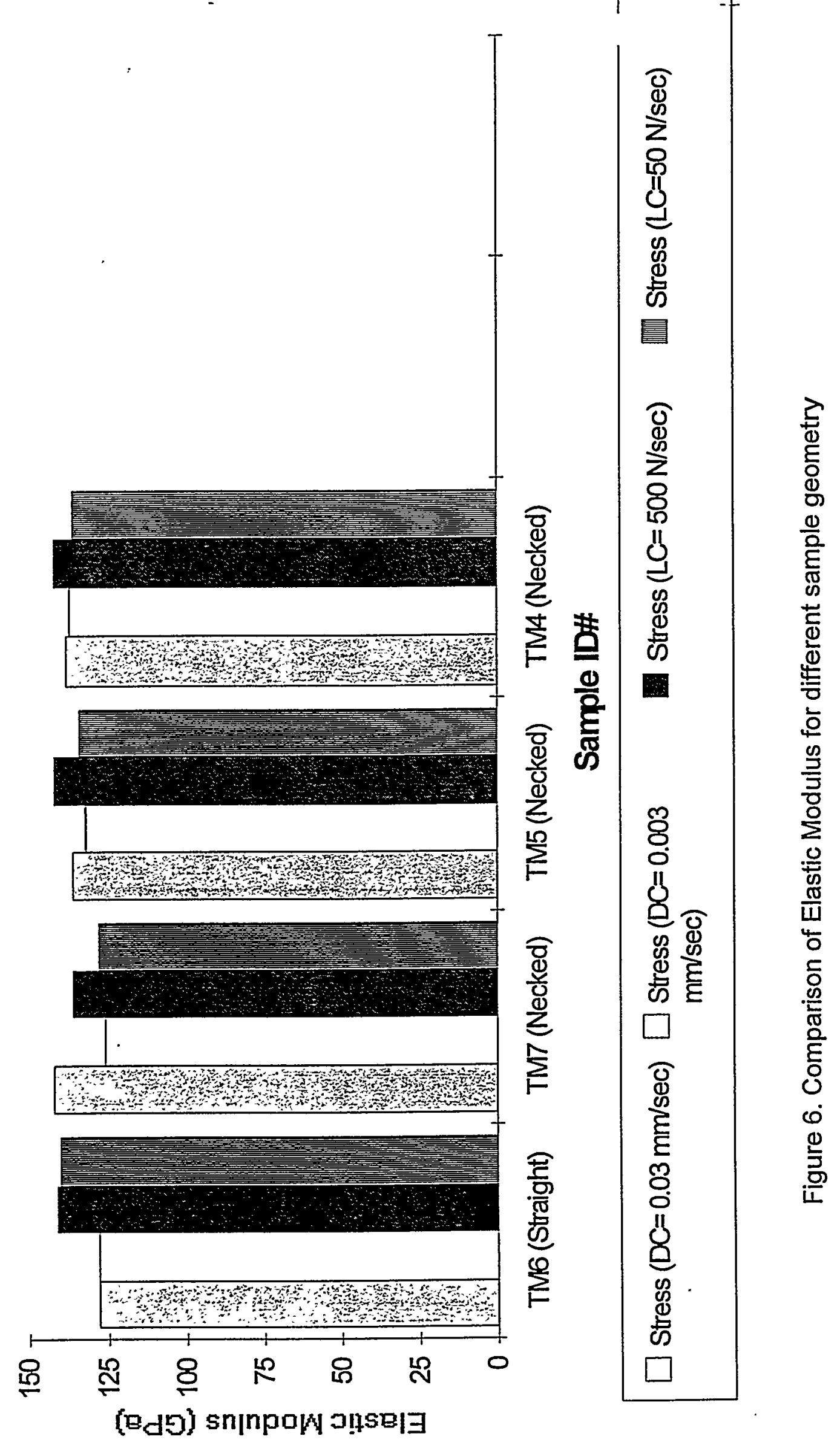




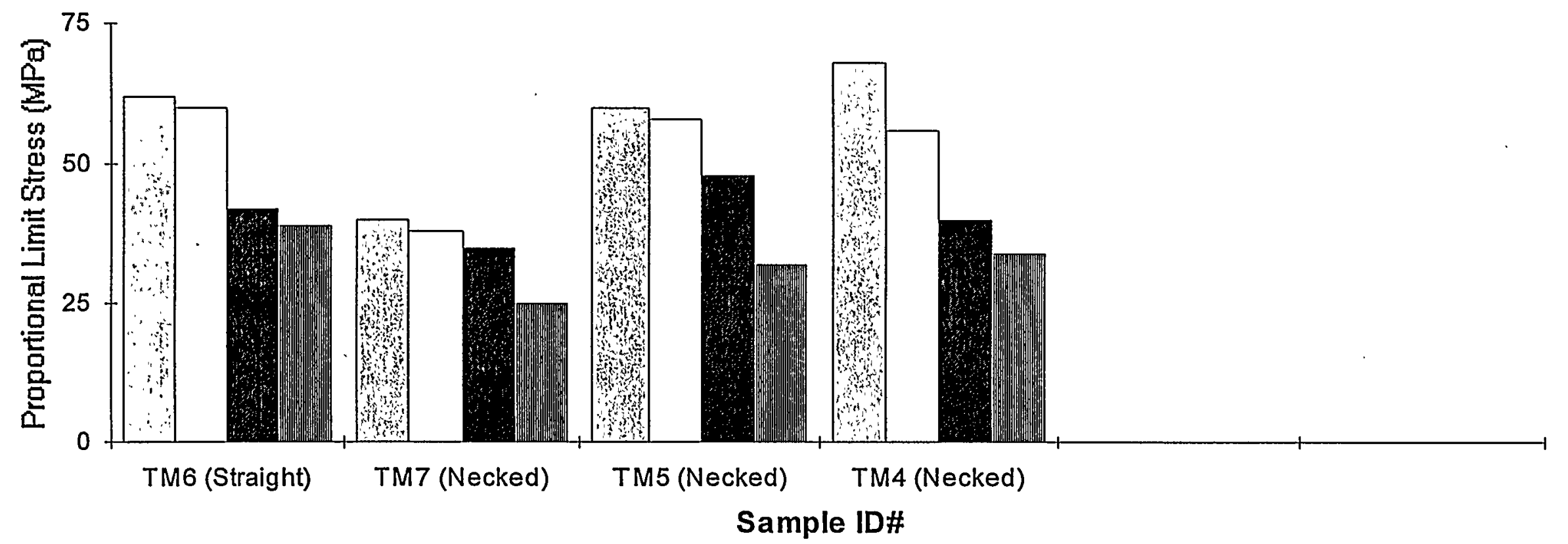

\begin{tabular}{|c|c|c|c|}
\hline$\square$ Stress $(D C=0.03 \mathrm{~mm} / \mathrm{sec})$ & $\begin{array}{l}\square \text { Stress }(D C=0.003 \\
\mathrm{mm} / \mathrm{sec})\end{array}$ & Stress (LC $=500 \mathrm{~N} / \mathrm{sec})$ & Stress ( $L C=50 \mathrm{~N} / \mathrm{sec}$ ) \\
\hline
\end{tabular}

Figure 7. Comparison of Proportional Limit Stress for different sample geometry And finally I would like to say: STOP ALL FRENCH NUCLEAR TESTING IN THE PACIFIC! 


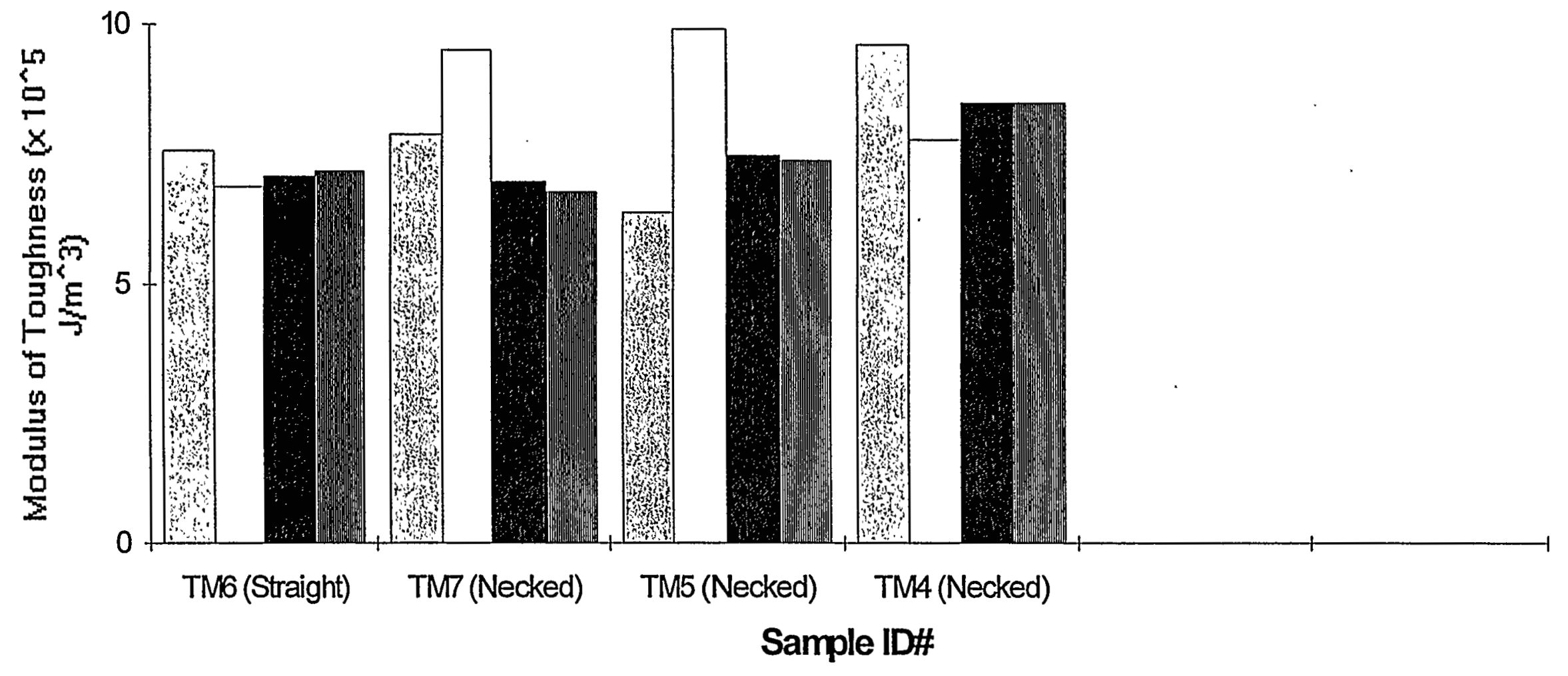

Stress $(\mathrm{DC}=0.03 \mathrm{~mm} / \mathrm{sec})$
$\square$ Stress $(\mathrm{DC}=0.003 \quad$ Stress $(\mathrm{LC}=500 \mathrm{~N} / \mathrm{sec})$$\quad \square$ Stress $(\mathrm{LC}=50 \mathrm{~N} / \mathrm{sec})$

Figure 8. Comparison of Modulus of Toughness for different sample geometry 


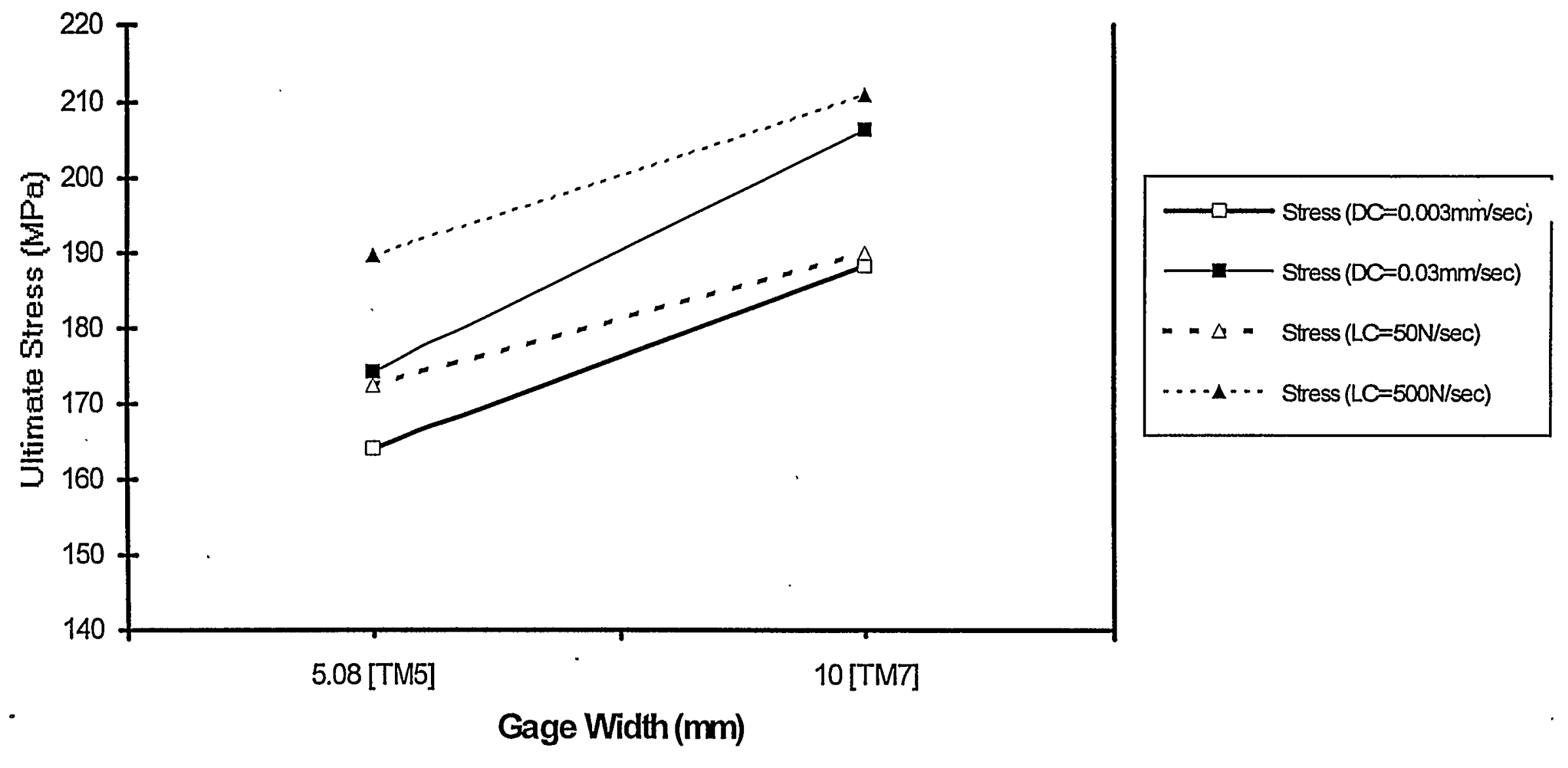

Figure 9. Variation of Ultimate Stress versus Gage Width (condition : For Constant Gage Length $=60 \mathrm{~mm}$ ) 


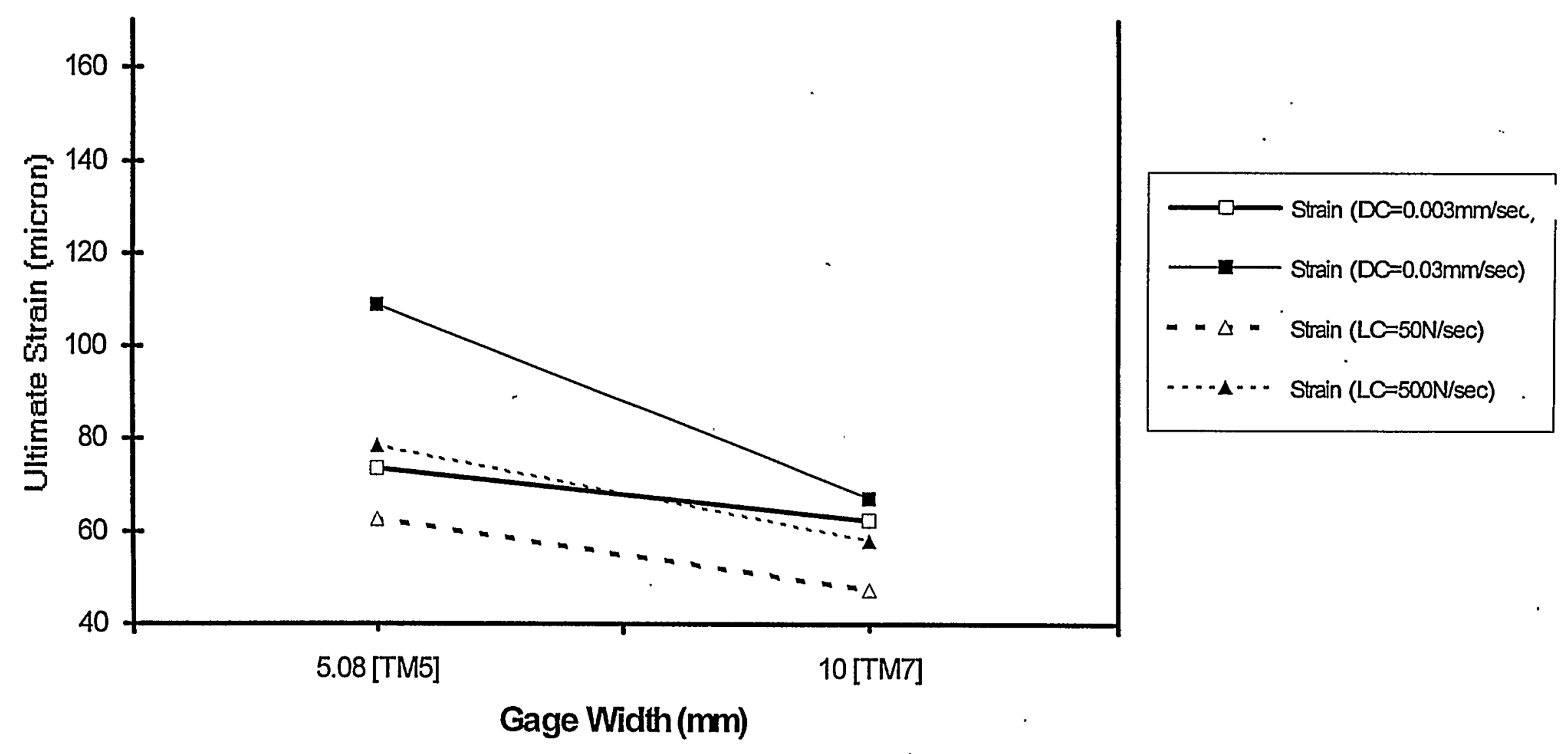

Figure 10. Variation of Ultimate Strain versus Gage Width (condition : For Constant Gage Length $=60 \mathrm{~mm}$ ) 


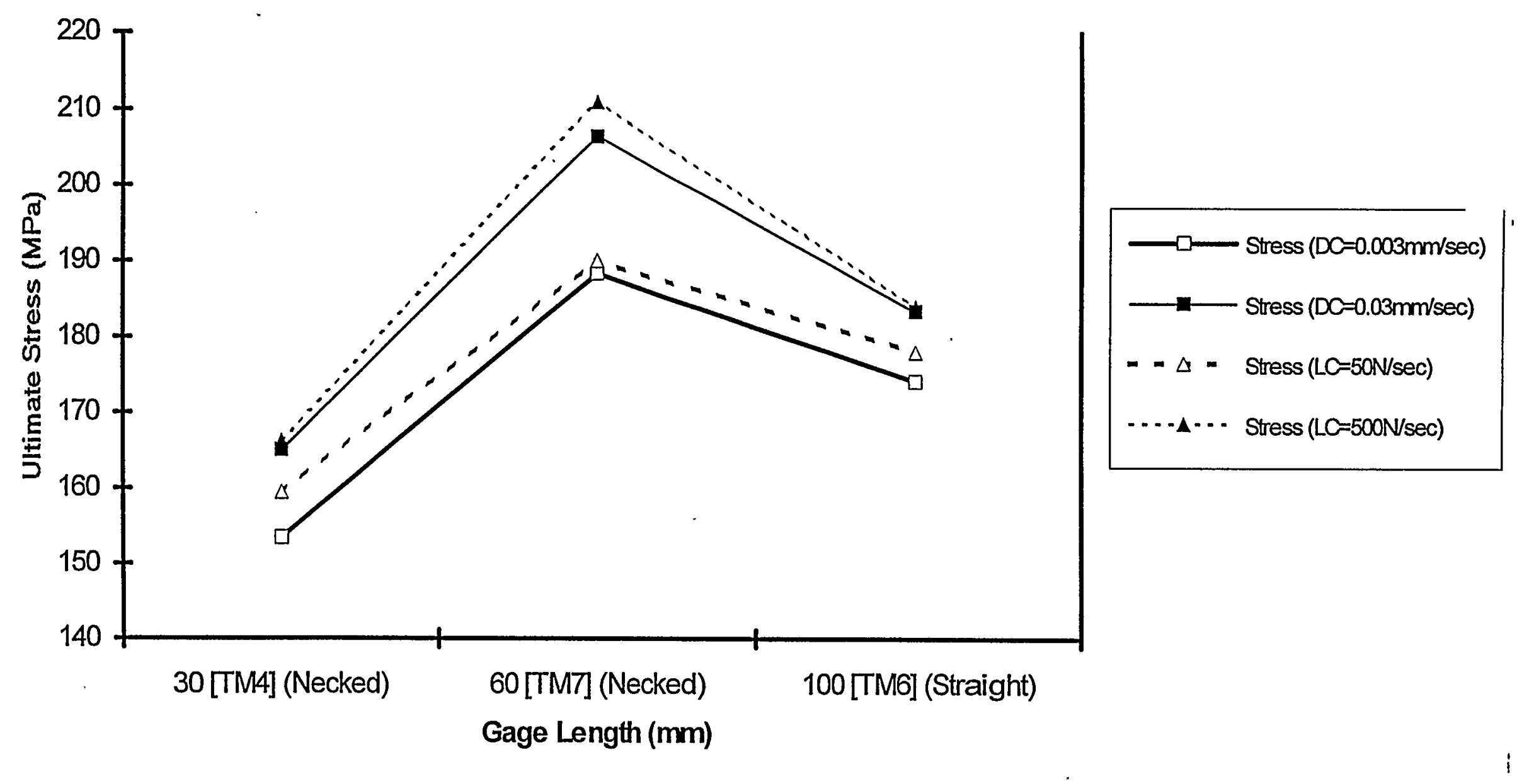

Figure 11. Variation of Ultimate Stress versus Gage Length (condition : For Constant Gage Width $=10 \mathrm{~mm}$ ) 


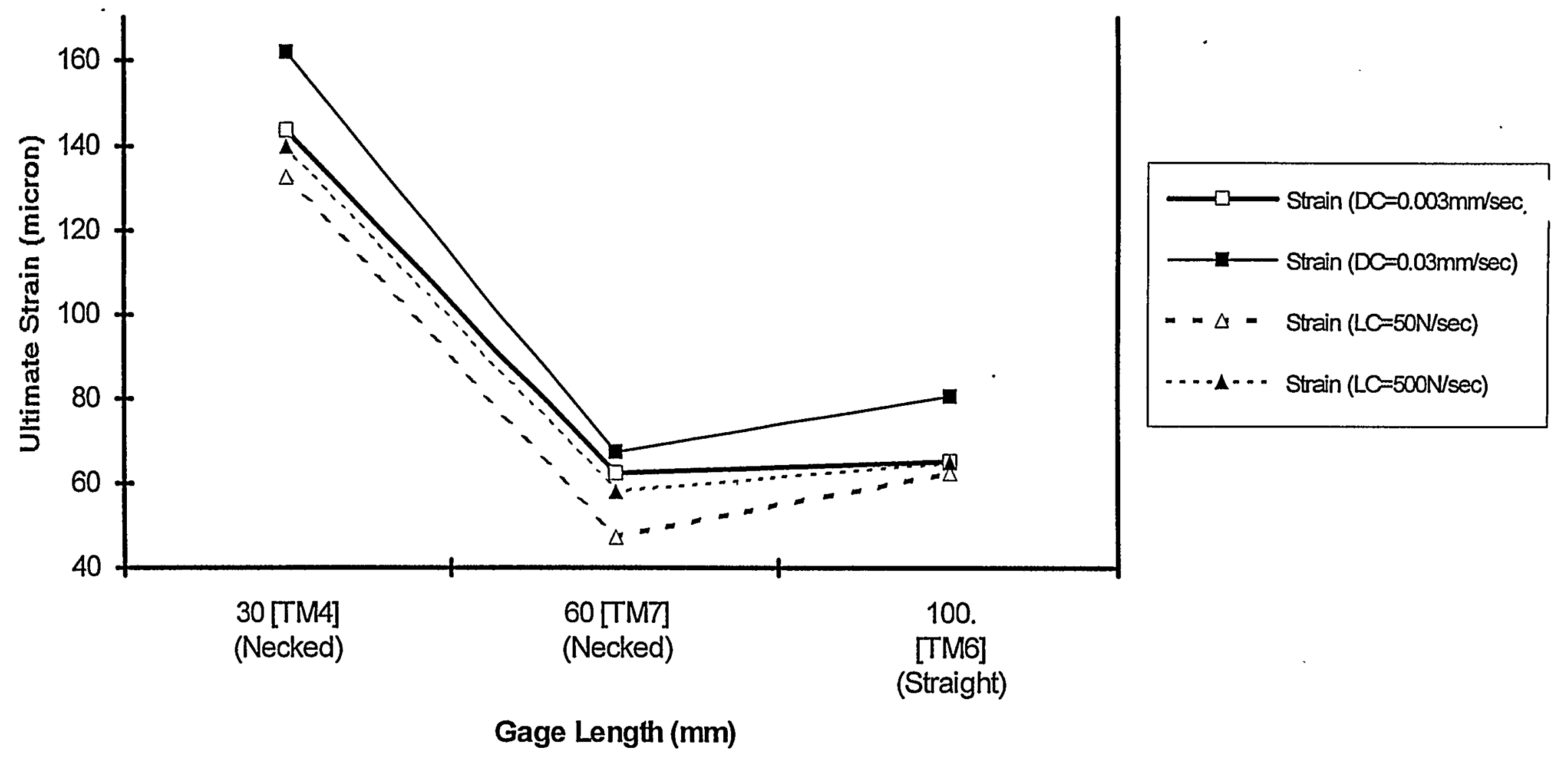

Figure 12. Variation of Ultimate Strain versus Gage Length (condition : For Constant Gage Width $=10 \mathrm{~mm}$ ) 

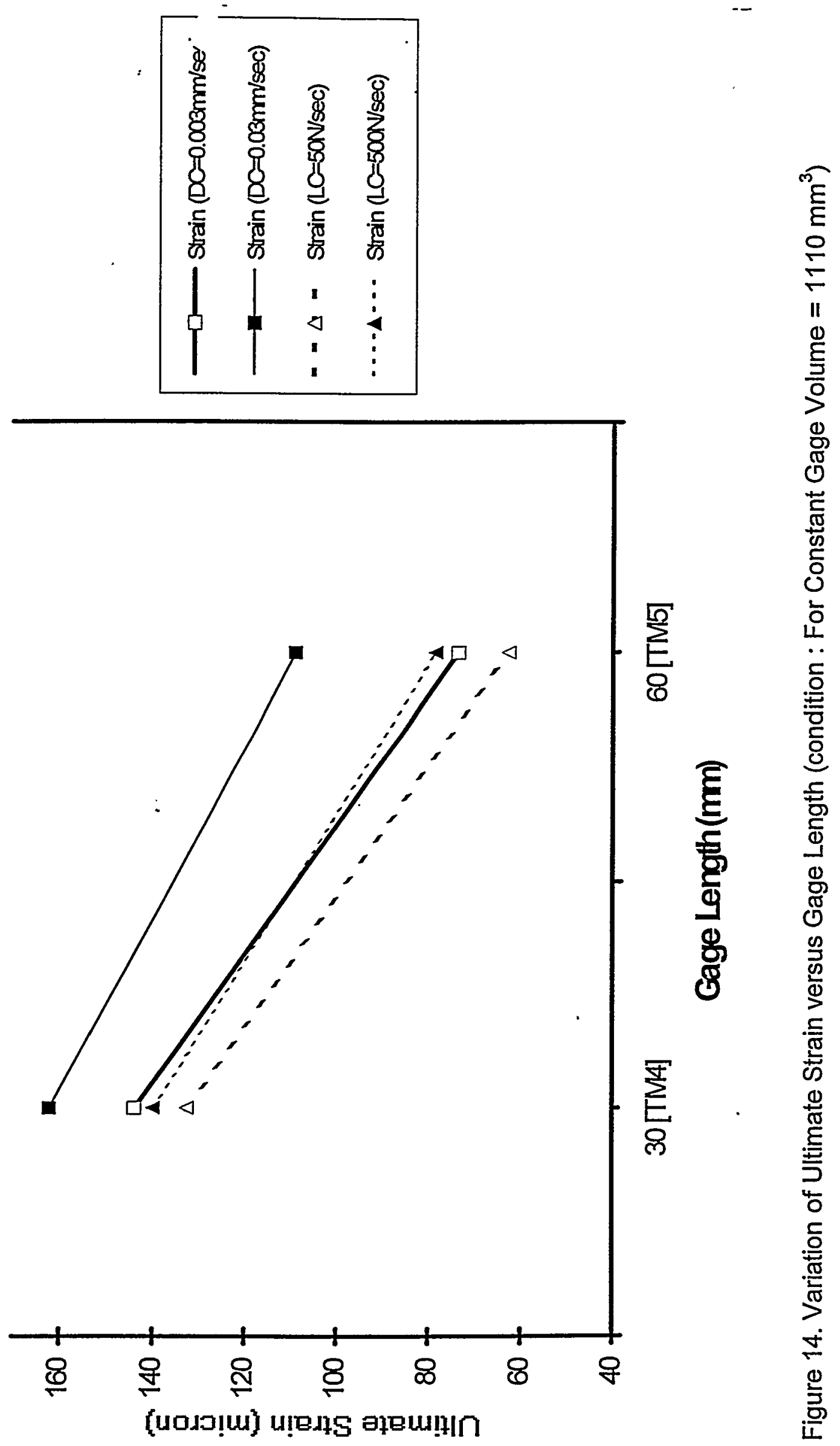


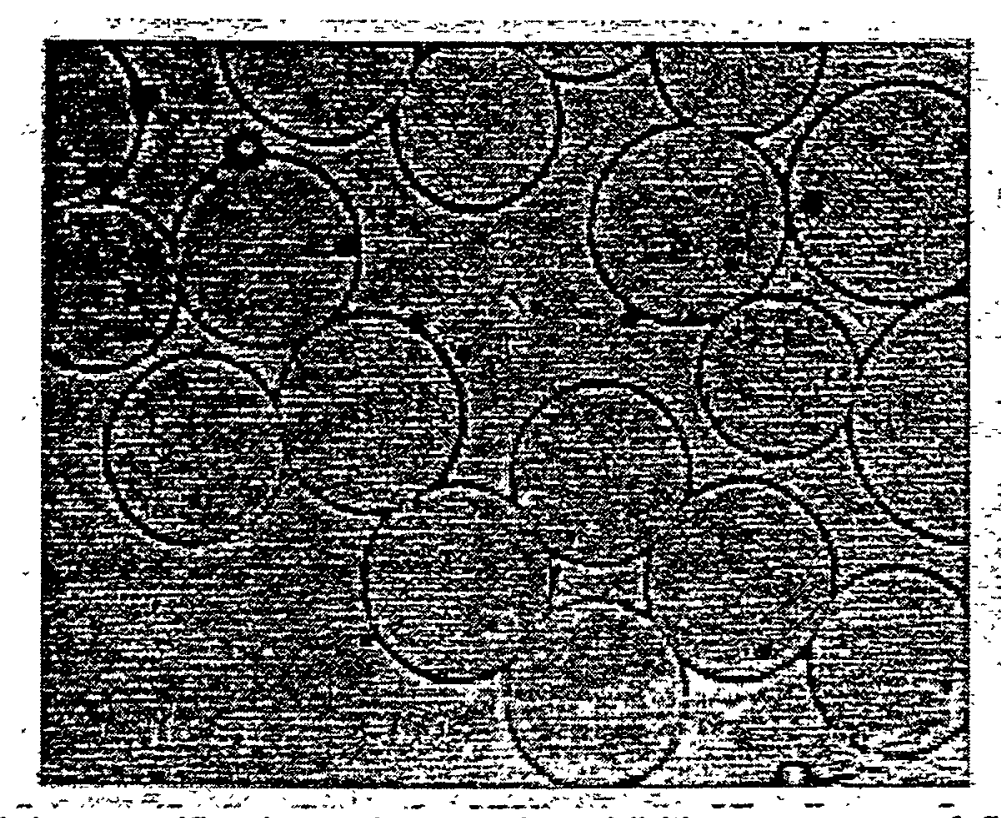

Figure 15. High magnification micrograph exhibiting a range of fiber diameters from $\sim 10-20 \mu \mathrm{m}$.

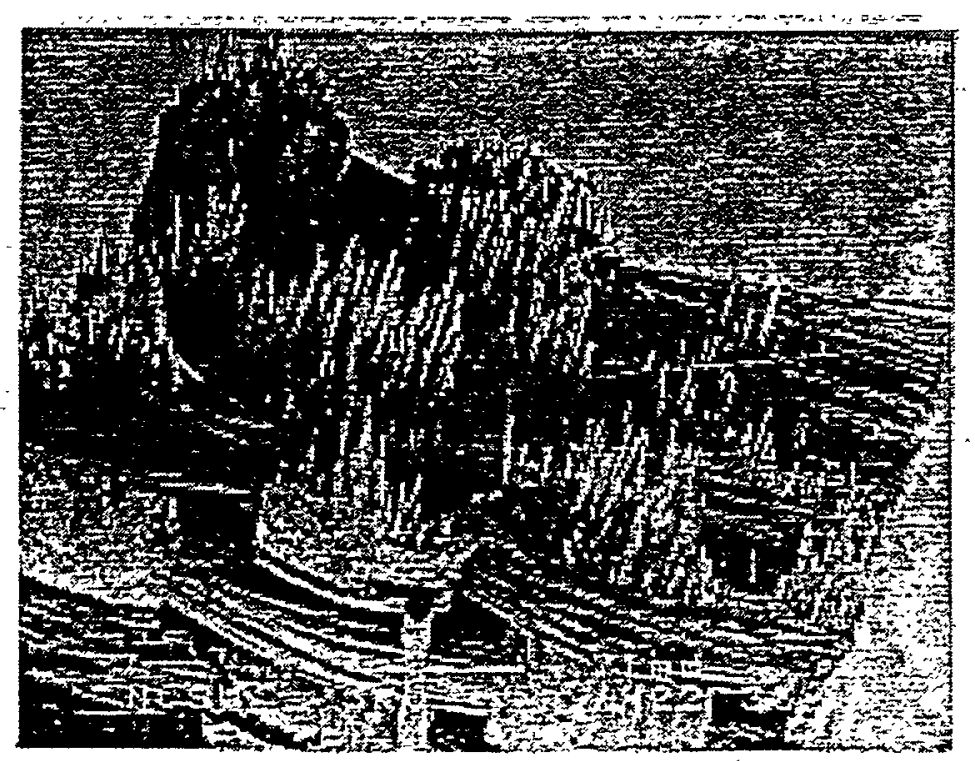

Figure 16. A magnified view of the fractured surface of a specimen which was tensile tested at ambient temperature 


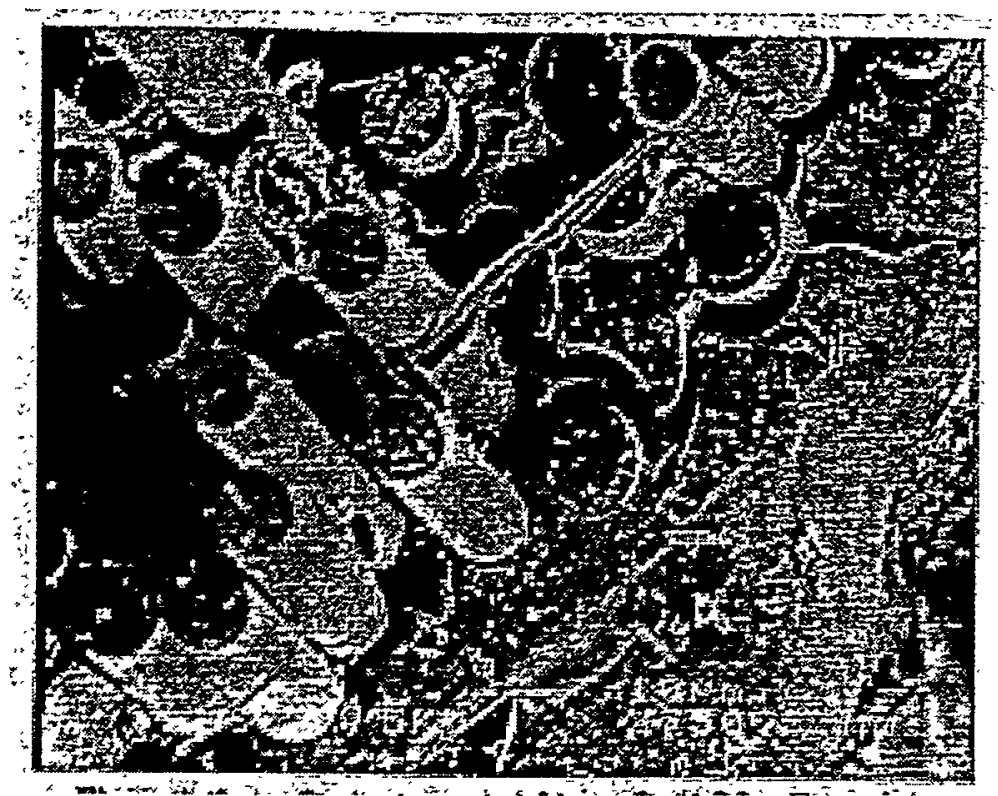

Figure 17. An as-fracture cross-section surface of the composite.

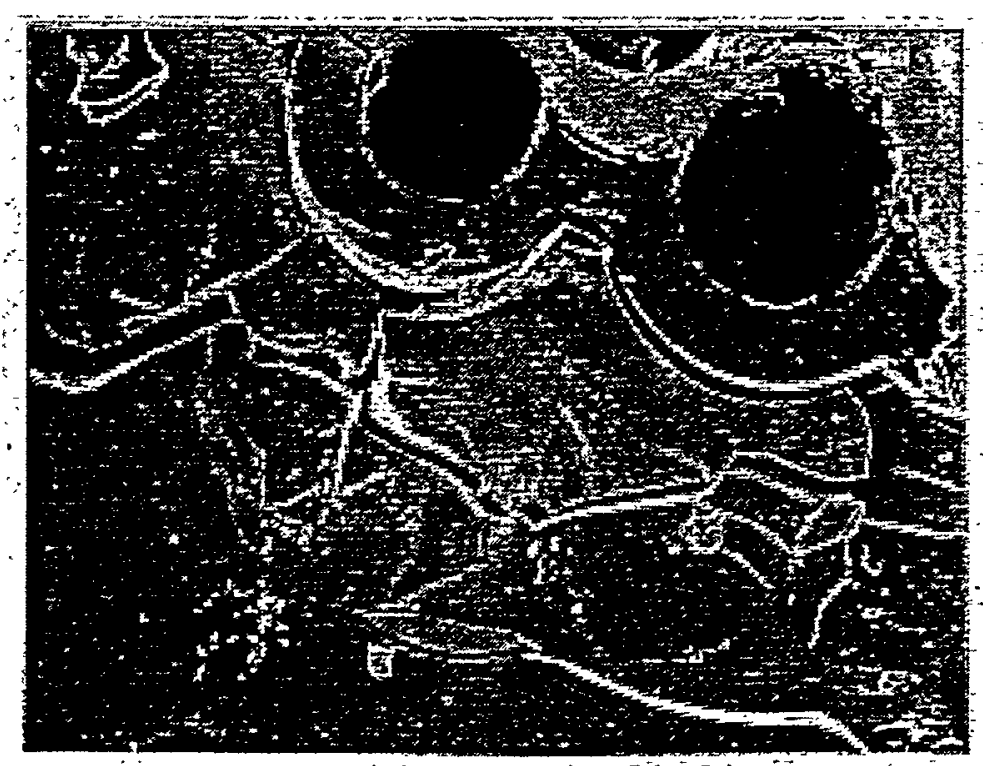

Figure 18. Fractograph showing the process of crack propagation and deflection 


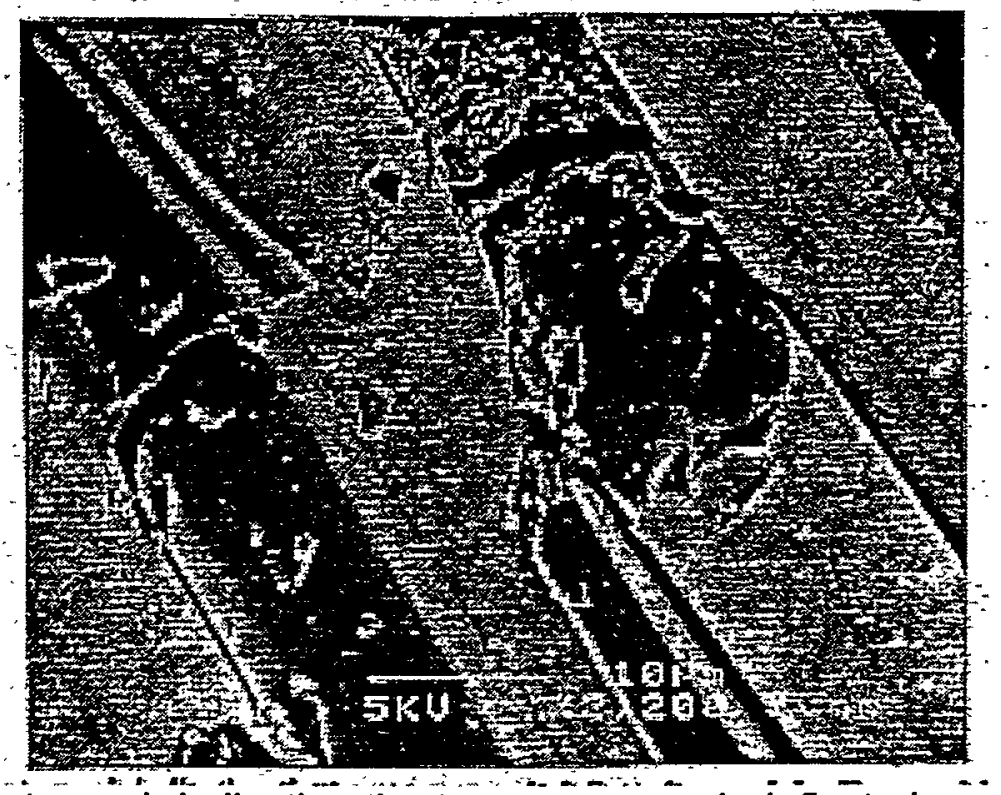

Figure 19. Fractograph indicating the transverse crack deflected around the fibers and fiber bridging.

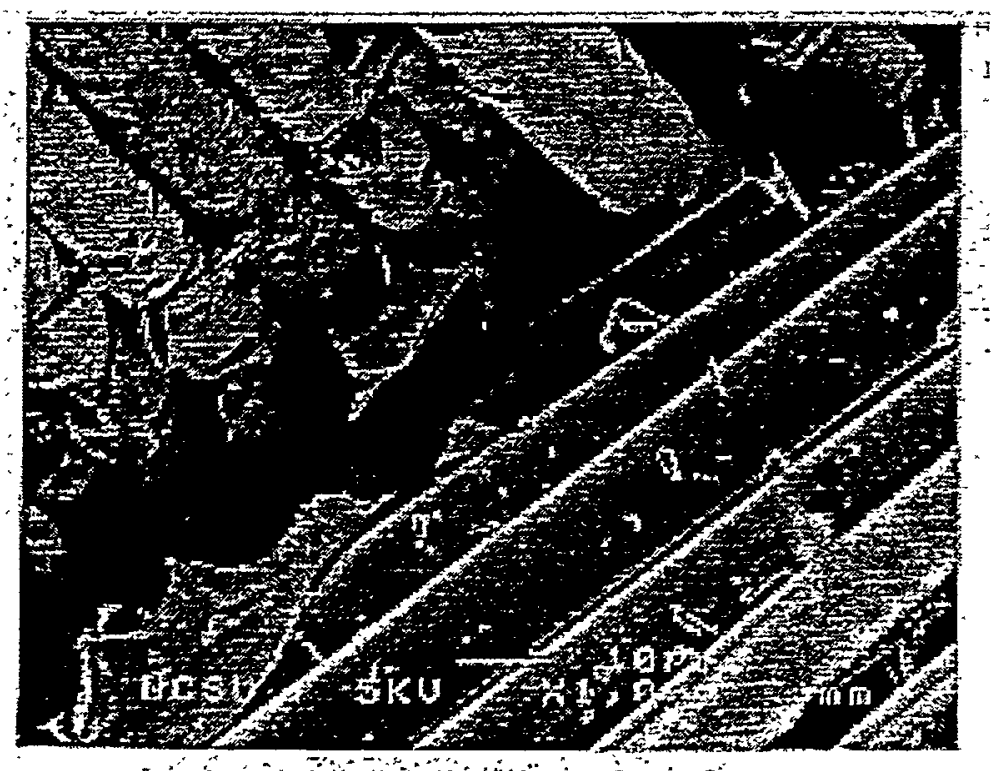

Figure 20. Failure surface showing severely damaged load carrying fiber (longitudinal tows) surface compared to transverse fiber surface. 


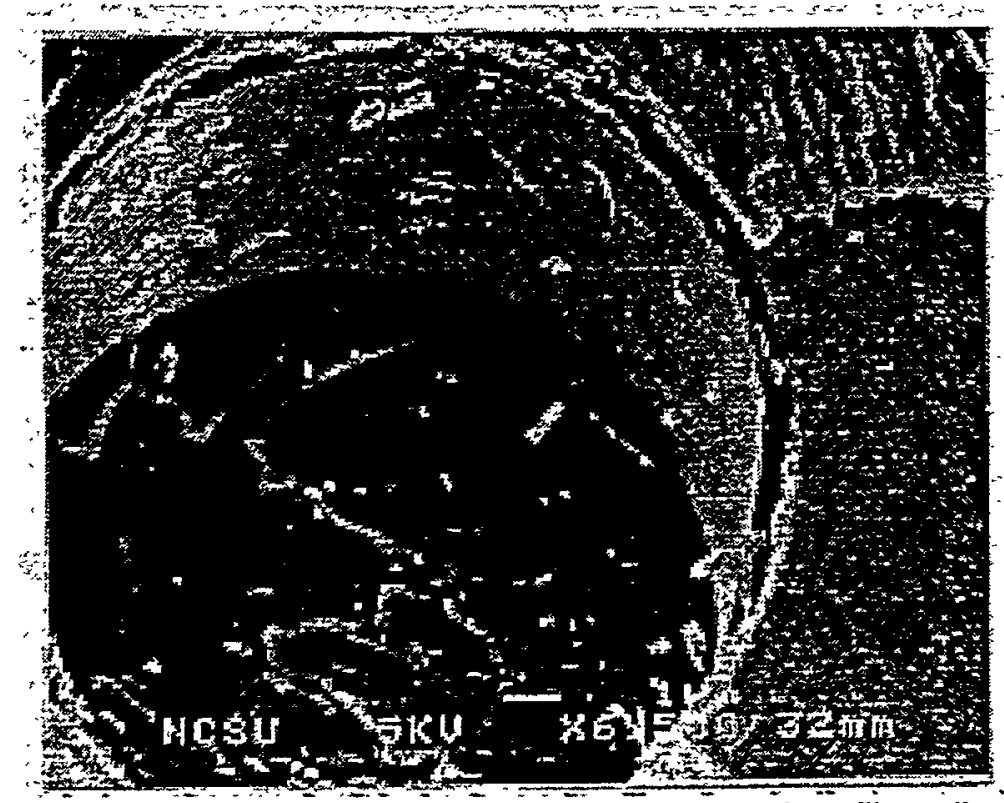

Figure 21. High resolution micrograph of the load carrying fiber (longitudinal tow) pull-out region.

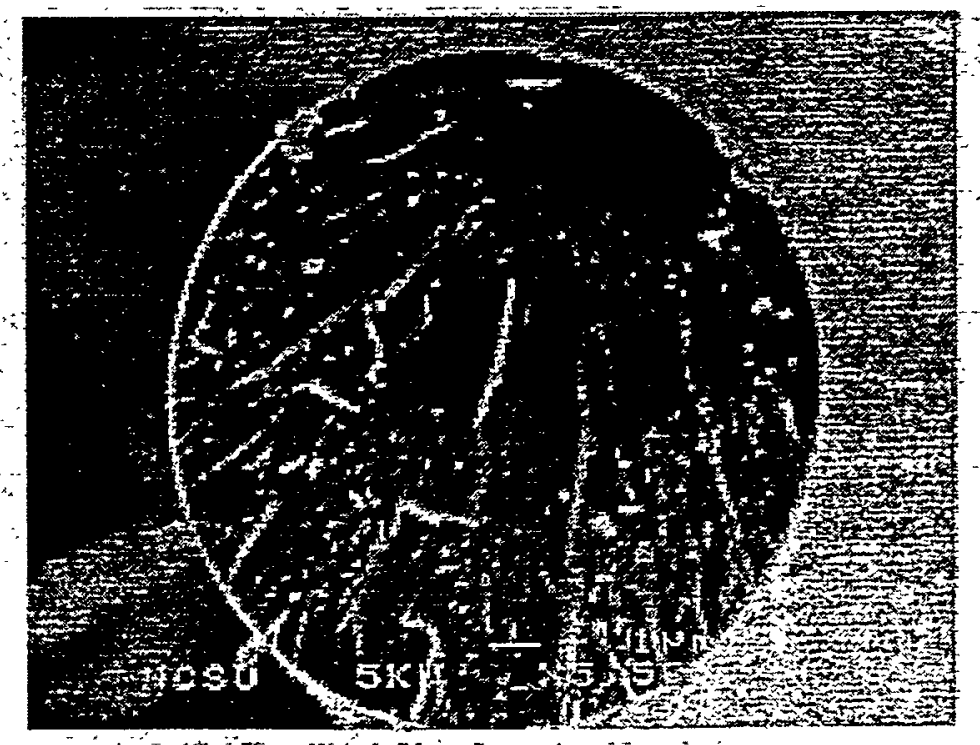

Figure 22. A typical surface morphology of fractured fiber in the composites which was tensile tested at ambient temperature. 